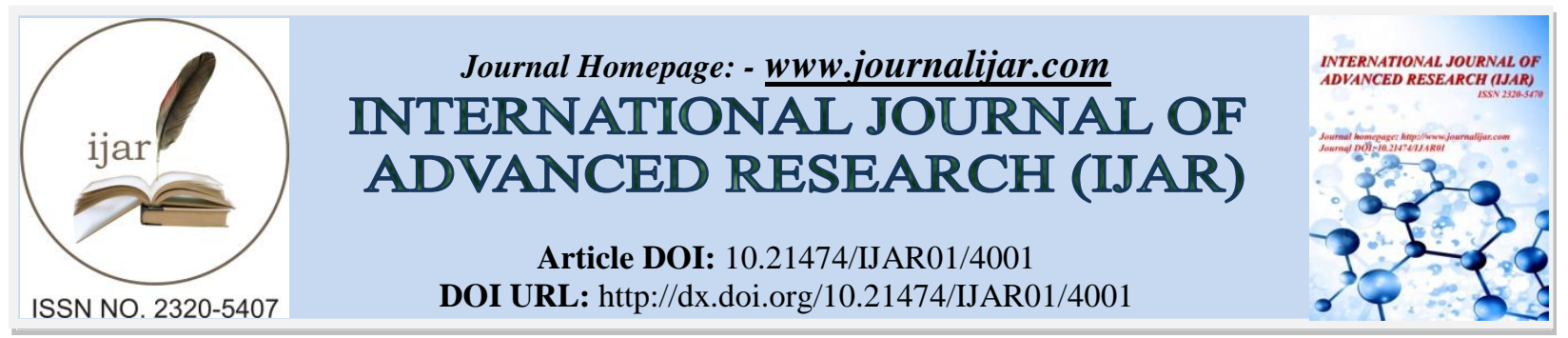

RESEARCH ARTICLE

\title{
KNOWLEDGE, ATTITUDE AND PRACTICE OF DENTAL ADHESIVE USE AMONG DENTAL PRACTITIONERS OF CHENNAI CITY- A CROSS SECTIONAL STUDY.
}

Subashri A.

II BDS student, Prosthodontics department, Saveetha Dental College, Chennai - 600077.

\section{Manuscript Info}

Manuscript History

Received: 12 February 2017

Final Accepted: 08 March 2017

Published: April 2017

Key words:-

dental practitioners, denture adhesive, resorption, clinical practice.

\section{Abstract}

Aim: The aim of this study is to evaluate the knowledge, attitude and practice of dental adhesive use among dental practitioners of Chennai city.

Objective: A conflicted topic in both clinic practice and dental education is the use of adhesive and their roles in prosthodontics. The use of adhesive are known to be poor aids to provide retention to an ill fitting prosthesis by few dentists. These views have raised many conflicts among the dentists about the use of dental adhesive.

Background: This study is done among 150 dental practitioners in the city of Chennai by circulating self administered questionnaires. Some questionnaires were also filled through online. The data will be reported in the SPSS online software to tabulate the percentages and mean.

Method: The questionnaires were distributed among many dental clinics and also through online forms. The responses were recorded and the data imported to spss online software for the results.

Reason: This study tries to solve the conflict idea between various dental practitioners regarding the use of dental adhesive and their role is prosthodontics.

Result: A mixed response was obtained about the subjects knowledge about the denture adhesive. According to the attitude type questions average responses were elicited. However majority of them used denture adhesive in their practice.

Copy Right, IJAR, 2017,. All rights reserved.

\section{Introduction:-}

Restoration of the masticatory function is the main goal of prosthetic treatment ${ }^{1}$. Major challenge is prosthodontics along with the restoration is improving denture retention and stability ${ }^{2}$. Augmentation of stability and support of denture can be done by using dental adhesive. This absorbs saliva and swell up to create a strong hold between the denture and underlying tissues ${ }^{3}$.

In the late $18^{\text {th }}$ century dental adhesive were introduced in dentistry. First it was issued in 1913 followed in 1920 and 30 's ${ }^{4}$. In $1035^{\text {th }}$ edition of Accepted dental remedies, adhesive have been referenced by the American dental association. From then adhesive are been used as a aim to provide viscosity and stickiness by absorbing water and improving the retention of the dentures. 
Retention of complete denture is proved to be improved by using dental adhesive. $12 \%$ of the complete denture wearers used adhesive stated by Tarbet and Grossman ${ }^{5}$. In 1996, 75\% of the dentists recommended dental adhesive which was used by more than 5 million Americans ${ }^{6}$. Some elderly patients are suggested to use dental adhesive during first weeks of wearing new denture by few dental surgeons to enhance the retention and supply confidence to patients. Dental adhesive can also minimise the discomfort for patients with new dentures.

One of the most important treatment option in prosthodontics is complete denture. But retention of complete denture has always been a problem for the dental practitioners. When it is not possible to obtain retention in complete denture dental adhesives are used. Even when surgical ridge augmentation procedures are not possible due to patient's systemic condition, economical status or age dental adhesives are used ${ }^{7,8}$.

Adhesives are found to be more advantageous, satisfactory and comfortable for the patients while chewing and speaking ${ }^{9}$. Without these adhesives all these factors are less applicable to the patients ${ }^{10}$. The utilisation of the dental adhesives by the denture wearer patients is more likely acceptable because they produce greater strength and stability to the denture. However they are not wholly preferred by the dental practitioners.

\section{Materials And Methods:-}

A self administrated questionnaire was developed to conduct this descriptive, cross sectional study. A list of dental practitioners in the city of chennai was obtained. Investigators personally approached the 150 dental practitioners and requested them to complete the comprehensive, close ended, self administered questionnaire. One hundred and forty two dental practitioners participated in this study. Therefore the response rate was $94.66 \%$.

The questionnaire prepared gathered all the information of the dental practitioners such as their socio- demographic details, duration of clinical experience, knowledge about the dental adhesives and their recommendations. This questionnaire included five knowledge related questions such as mechanism, composition, indications etc. Four attitude type questions such as the use, patient's education, perceived necessity etc. These questions made the practitioner take a strong decision or agreement on their opinion. Finally practice questions were included which consists of the patient recall, evaluation and instructions.

To draw the percentage and evaluate the mean points the data were imported in the SPSS software programme. The results were divided into groups such as the age, gender, qualifications for better interpretations. The questionnaire is as follows:

\section{Results:-}

The sociodemographic characteristics are given in table 1. The questionnaire was circulated among 150 dentist, out of which 108 participated. Therefore the response rate was $72 \%$. Majority of the dentist participated were females (76\%). The age group of 21-30 were found to be more than the other two groups. Greater part of the study includes the dentist with B.D.S qualification with the most of 1-10 years of experience. 


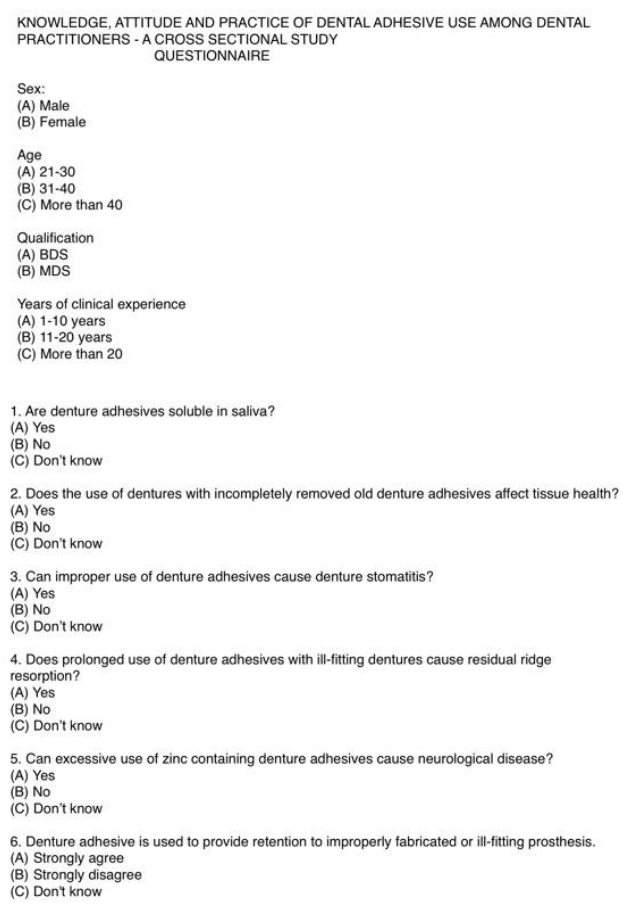

Table No:1- Socio- demographic details.

\begin{tabular}{|l|l|}
\hline Variables & Number( percentage) \\
\hline $\begin{array}{l}\text { Age } \\
\text { 1. } 21-30 \\
\text { 2. } 31-40 \\
\text { 3. More than } 40\end{array}$ & $\begin{array}{l}70(65 \%) \\
29(27 \%)\end{array}$ \\
\hline $\begin{array}{l}\text { Sex } \\
\text { 1. Male } \\
\text { 2. Female }\end{array}$ & $26(24 \%)$ \\
\hline $\begin{array}{l}\text { Qualification } \\
\text { 1. BDS } \\
\text { 2. MDS }\end{array}$ & $82(76 \%)$ \\
\hline $\begin{array}{l}\text { Years of experience } \\
\text { 1. } 1-10 \\
\text { 2. } 11-20\end{array}$ & $88(82 \%)$ \\
\hline 3. More than 20 & $20(18 \%)$ \\
\hline
\end{tabular}

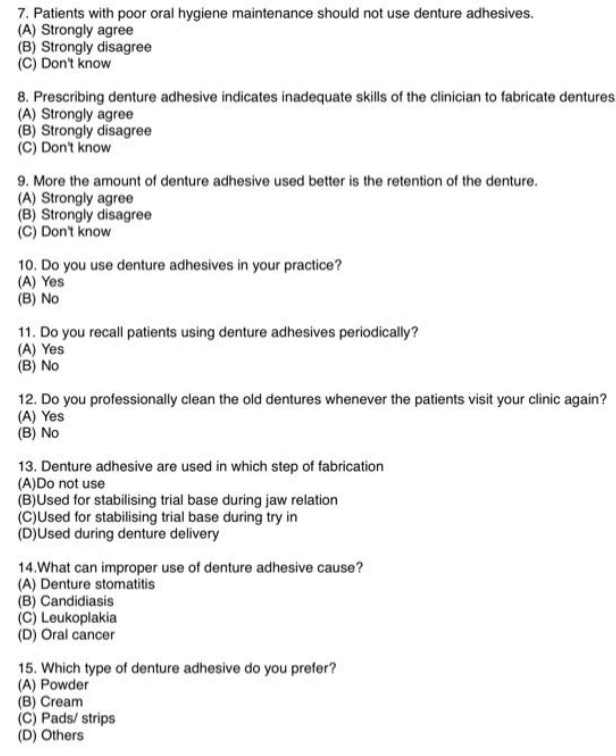

Figure No:3- Knowledge based questions.

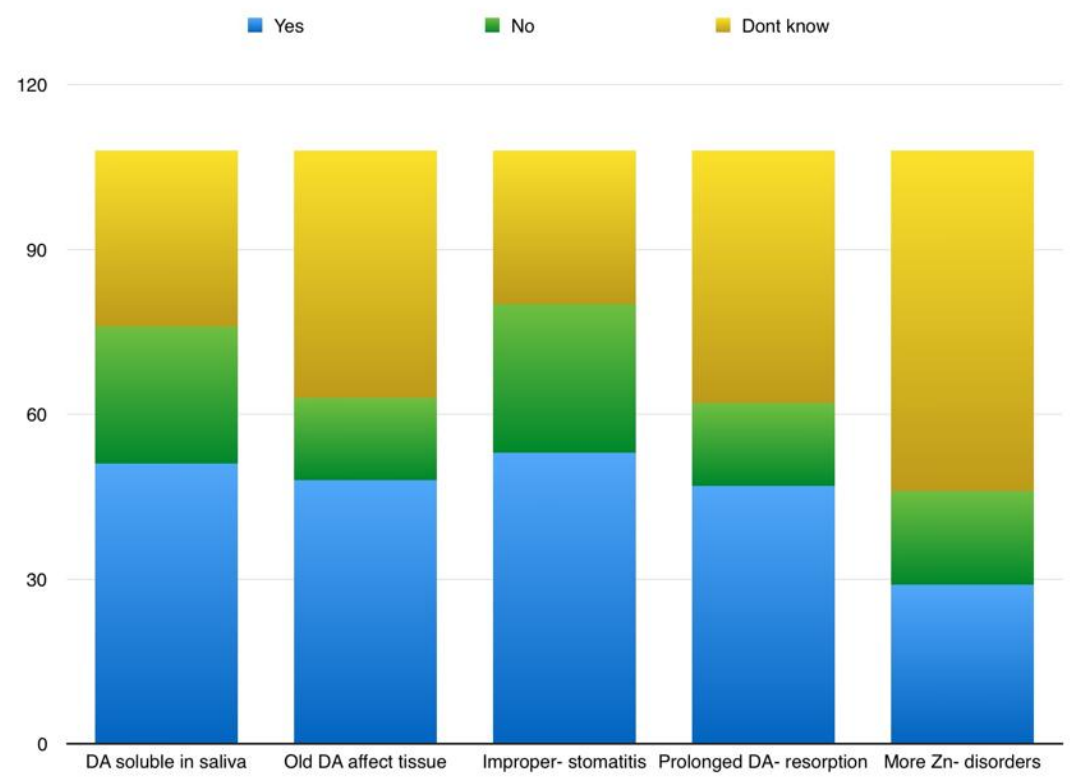

Fig.3 shows the dentist's knowledge on the use of denture adhesive. When they were questioned whether denture adhesive is soluble $23 \%$ answered wrongly. Similarly $42 \%$ didn't know that using the old denture adhesive affects the tissue health. Majority of them knew that improper use of denture adhesive can cause denture stomatitis. A mixed response was obtained when the subjects were asked does the prolonged use of denture adhesive cause residual bone resorption. Many of them didn't know that by using denture adhesive with more Zinc content causes severe neurological disorders. 
In Figure.4, the questions are related to the practitioner's attitude towards the usage of denture adhesive. The options made the subject think deep and answer either they agree or disagree. Nearly $50 \%$ of the strongly disagreed that the denture provided retention to ill- fitting prosthesis. $57 \%$ of the practitioners strongly agreed that denture adhesive should not be given to the patients with poor oral hygiene maintenance. Denture adhesive is given by the clinician who have inadequate skills, this is strongly disagreed by $80 \%$ of the subjects. Similarly many disagreed to the statement which says increase in denture adhesive causes increase retention.

In table 2, practice related questions were asked to the dental practitioners. More than half of the subjects use denture adhesive in their treatment. A mixed response was obtained when asked about recalling patients periodically. Positive response was found when asked about professionally cleaning the denture when the patient comes for revisit.

Figure No 4:- Practitioners attitude towards DA.

Table no 2:- Clinical practice related questions

\begin{tabular}{|l|l|l|}
\hline Questions & Yes & No \\
\hline Do you use denture adhesives in your practice? & 72 & 36 \\
\hline Do you recall patients using denture adhesives periodically? & 53 & 55 \\
\hline Do you professionally clean the old dentures whenever the patients visit your clinic again? & 64 & 44 \\
\hline
\end{tabular}

\section{Discussion:-}

The main reason to prescribe denture adhesive as stated by a panel of prosthodontics to improve denture stability and retention and thereby provide confidence to the patient ${ }^{11}$. Denture adhesive is applied on the tissue surface of the denture and is referred to be non- toxic and soluble material. The results obtained said that nearly $30 \%$ of the practitioners didn't know about the solubility of the denture adhesive. The dentists should have a thorough knowledge about denture adhesive so that they can educate the denture wearing patients. Patient expect the dentist to know the correct information about the product and clear all their doubts if any.

In a study by Stafford et al it is indicated that denture adhesive could influence oral flora by causing imbalance in the flora ${ }^{12}$.According to a study, prolonged use of ill fitting dentures not only affects the soft tissue but also speeds up the resorption of alveolar ridge ${ }^{13}$. Moderation of the indications and contradictions for advising the use of denture adhesive is by understanding the basic techniques like the mechanisms ${ }^{14,15,16}$ which was lacking among many dentists leading to the misuse of the products.

Recently there have been many serious cases reported about the neurotoxicity caused by the excess zinc containing denture adhesives. Unfortunately nearly $57 \%$ of the dentists are unaware about this information which caught the attention of the dental fraternity ${ }^{17}$. The sole source of the neurological disorders in using the excess $\mathrm{Zn}$ denture adhesive was identified by Nations et al and Hedera et $\mathrm{al}^{18}$. Recently a study found that excess $\mathrm{Zn}$ adhesive is also a potential cause for copper deficiency myelopathy ${ }^{19}$.

Patients with xerostomia are benefited with the well hydrated denture adhesive because it provides cushioning and lubricating effect. Hence it reduces functional irritation to the supporting tissue preventing for stomatitis and ulceration ${ }^{20}$.

World wide dentists have not accepted denture adhesives in their practice. This may be due to the lack of knowledge or the minimal attention given to it during undergraduate level or continuing dental education programs ${ }^{21}$. This must be enhanced and the importance, knowledge and advantages about the denture adhesives should be given to the practitioners.

The greatest advantage of the denture adhesive depends on its proper usage. In the current study,72 dentists used denture adhesive; well above the percentage recorded by the Temel ${ }^{22}$. This percentage has been increased because of its low cost and easy availability.

\section{Conclusion:-}

The proper usage of denture adhesive can make the patient comfortable but not intend as an enhancer for ill fitting dentures. Before using the denture adhesive it is important to note down the patient's status, so that after application 
of the denture adhesive differ can be found out. According to the responses obtained in our study we conclude by although denture adhesive are used by many dental practitioners, but unfortunately many of them do not have a thorough knowledge about it. By attending the continuing education programs the practitioners can gain knowledge about the adhesive, many other updates and implement in their treatment for betterment of the patient.

\section{References:-}

1. Goncalves, et al. Denture adhesives improve mastication in denture wearers. Int J Prosthodont 2014;27(2):140146.

2. Figueiral $\mathrm{MH}$, et al. The effect of different adhesive materials on retention of maxillary complete dentures. Quintessence Publishing Co. Inc 2011;24(2):175-177.

3. Ahlawat P, Darki HA, Zahir Y, Saini D. Survey on availability and usage of denture adhesives in Malaysia: a preliminary study. Asian J Pharma Hea Sci 2012;2(1):286-289.

4. Ozcan M, Kulak Y, Arikan A, Silahtar E (2004) The attitude of complete denture wearers towards denture adhesives in Istanbul. J Oral Rehabil 31(2):131-134

5. Tarbet WJ, Grossman E. Observations of denture-supporting tissue during six months of denture adhesive wearing. J Am Dent Assoc 1980;101:789-91.

6. Grasso JE. Denture adhesives: Changing attitudes. J Am Dent Assoc 1996;127:90-6.

7. Musani Smita, Dugal Ramandeep, Kothavade Mukund (2010) A review of denture adhesives used in the dental profession. Annals and essences of dentistry 3:129-133

8. Giulio Preti (2011) Prosthetic rehabilitation part II: technical procedures. Quintessence Publishing Co, Ltd. United Kingdom, p 103-104

9. Psillakis JJ, Wright RF, Grbic JT, Lamster IB (2004) In practice evaluation of a denture adhesive using a gnathometer. J Prosth- odont Dec 13(4):244-250

10. Kelsey CC, Lang BR, Wang RF (1997) Examining patients' responses about the effectiveness of five denture adhesive pastes. J Am Dent Assoc 128:1532-1538

11. Slaughter A, Katz RV, Grasso JE (1999) Professional attitudes towards denture adhesive —a Delphi technique survey of aca- demic prosthodontics. J Prosthet Dent 82:80-89

12. Stafford GD, Russel C (1971) Efficiency of denture adhesives and their possible influence on microorganisms. J Dent Res 50:832-836

13. Tarbet WJ, Grossman E (1980) Observation of denture-support-ing tissue during six months of denture adhesive wearing. J Am Dent Assoc 101:789-791

14. Adisman IK (1989) The use of denture adhesives as an aid to denture treatment. J Prosthet Dent 62:711-715

15. Grasso SE (1996) Denture adhesives: changing attitudes. J Am Dent Assoc 127:90-96

16. Shay K (1991) Denture adhesive. J Am Dent Assoc 122:70-76

17. Lamb DJ (1980) Denture adhesives: a side effect. J Dent 8:35-42

18. Nations SP, Boyer PJ, Love LA, Burritt MF, Butz JA, Wolfe GI, Hynan LS, Reisch J, Trivedi JR (2008) Denture cream: an unu- sual source of excess zinc, leading to hypocupremia and neuro-logic disease. Neurology 71(9):639-643

19. Doherty K, Connor M, Cruickshank R (2011) Zinc-containing denture adhesive: a potential source of excess zinc resulting in copper deficiency myelopathy. Br Dent J 210(11):523-525

20. Shay K (1997). The retention of complete dentures. In: Zarb GA, Bolender CL Carlsson GE Boucher's prosthodontic treatment for edentulous patients, 11th ed. St. Louis: Mosby-Year Book, Inc., p 400-411

21. Zhao K, Cheng XR, Chao YL, LI ZA, Han GL (2004) Laboratory evaluation of a new denture adhesive. Dent Mater 20:419-424

22. Koksal Temel (2007). “A survey of dentists' attitudes toward Denture Adhesives”. OHDMBSC-Vol. 1 Martie; 33-39. 